\title{
Preparation of Triacetoneamine, II
}

\author{
G. Sosnovsky and M. Konieczny \\ Department of Chemistry, University of Wisconsin-Milwaukee \\ Milwaukee, Wisconsin 53201, USA \\ (Z. Naturforsch. 32 b, 338-346 [1977]; received November 29, 1976)
}

Triacetoneamine, Diacetoneamine, Mesityl Oxide, Acetonin, Diacetone Alcohol

The preparation of triacetoneamine (1) by the condensation of acetone with ammonia in the presence of calcium chloride is investigated. The progress of the reaction is monitored by gas chromatography. The effects of added ammonium chloride, the total amount of ammonia introduced, and the temperature of the reaction on the weight yield and purity of 1 are investigated. The optimized conditions for the preparation of 1 at $59{ }^{\circ} \mathrm{C}$ are described.

Recently ${ }^{1,2}$ we have reported an investigation of the preparation of 4-oxo-2,2,6,6-tetramethylpiperidine, triacetoneamine (1), by the condensation of acetone with ammonia in the presence of calcium chloride.

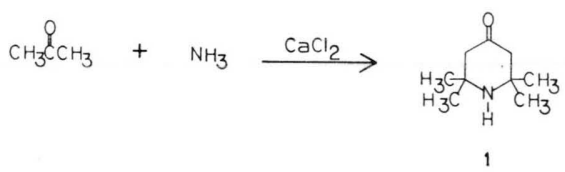

The effects of the extent and rate of stirring, the amount of ammonia introduced on the critical first day of the reaction, and the mesh size and quantity of calcium chloride on the purity and weight yield of 1 were studied. The progress of the reaction on a daily basis, and the purity of the crude product was monitored by gas chromatography. No phorone (2) could be at any time detected in the reaction mixture. In addition to triacetoneamine (1), acetonin (3), diacetone alcohol (4), mesityl oxide, and di-<smiles>CC(C)=CC(C)C(C)(C)C</smiles>

2
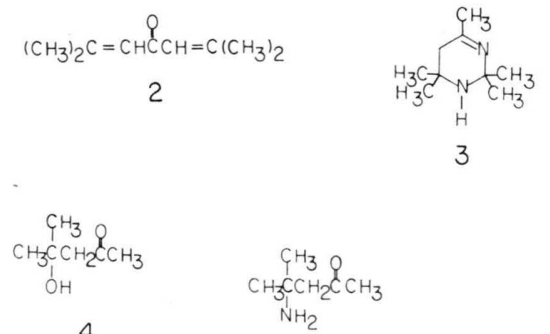

4

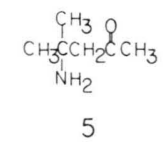

Requests for reprints should be sent to Prof. Dr. G. Sosnovsky, Department of Chemistry, University of Wisconsin-Milwaukee, Milwaukee, Wisconsin 53201, USA. acetoneamine (5) were also formed as by-products during the reaction. Now we wish to report the effects of added ammonium chloride, the total amount of ammonia introduced, and temperature of the reaction on the weight yield and purity of $\mathbf{1}$.

Matter $^{3}$ and Bradbury and coworkers ${ }^{4}$ reported that acetonin $(3)$ can be formed in a yield as high as $82-88 \%$ by the reaction of acetone with ammonia under pressure in the presence of a mixture of calcium chloride and ammonium chloride. Therefore, we investigated the effect of ammonium chloride on the purity of $\mathbf{1}$, and found that it was somewhat reduced, but not nearly as much as in the case when the reaction was performed with less than 400 grams calcium chloride per 1000 grams of acetone. In addition, the reaction mixture did not behave identical to that performed under the optimized conditions at room temperature ${ }^{2}$. Thus, the color of the reaction mixture was a darker red, and the viscosity was reduced. However, the reaction mixture never attained the heterogeneous state characteristic of reactions which lead to product 1 of inferior quality (see experiments 1-3). The results of these experiments are listed in Table I.

The total amount of ammonia introduced during the reaction was found to be critical. Theoretically, for 1000 grams of acetone, 98 grams $(5.8 \mathrm{~mol})$ of ammonia is needed. Simon and Vvedenski ${ }^{5}$ have reported that best results on the preparation of 1 from acetone in the presence of calcium chloride were achieved at $100-105 \%$ saturation with ammonia. However, it was now found ${ }^{2}$ that optimum 
Table I. The effect of ammonium chloride on the purity of $\mathbf{1}$.

\begin{tabular}{lcll}
\hline $\begin{array}{l}\text { Amount } \\
\text { of } \mathrm{CaCl}_{2}{ }^{\mathrm{a}} \\
{[\mathrm{g}]}\end{array}$ & $\begin{array}{l}\text { Amount } \\
\left.\text { of } \mathrm{NH}_{4} \mathrm{Cl}\right]^{\mathrm{a}} \\
{[\mathrm{g}]}\end{array}$ & $\begin{array}{l}\text { Purity } \\
\text { of } \mathbf{1}^{\mathrm{b}} \\
{[\%]}\end{array}$ & $\begin{array}{l}\text { Yjeld } \\
\text { of } \mathbf{1}^{\mathrm{d}} \\
{[\%]}\end{array}$ \\
\hline $400^{\mathrm{e}}$ & 0 & $85^{\mathrm{c}}$ & 48 \\
400 & 10 & $85^{\mathrm{c}}$ & 45 \\
400 & 100 & $72^{\mathrm{c}}$ & 35 \\
400 & 400 & $70^{\mathrm{c}}$ & 22 \\
\hline
\end{tabular}

a Per $1000 \mathrm{~g}$ of acetone. b As determined by gas chromatography. c The main impurity was acetonin (3). d Based on the amount of 1 obtained from the crude reaction mixture, without taking into account the unreacted acetone. e Optimized reaction conditions (see our first paper concerning triacetoneamine ${ }^{2}$ ).

results, as far as purity and weight yield are concerned, were obtained using 140 grams (8.2 mols) of ammonia, i.e. at $140 \%$ saturation with ammonia. In this case, no detectable amount of ammonia escaped from the reaction mixture during the course of the reaction. If less than that amount of ammonia was introduced, the purity of 1 increased slightly while the weight yield of 1 dropped considerably. However, if 147 grams $(8.6 \mathrm{~mol})$ of ammonia was introduced, the purity of 1 decreased sharply from $85 \%$ to $50 \%$ and, as a result, the yield of 1 was adversely affected. In this case, the reaction mixture reverted to heterogeneity during the final introduction of ammonia. Acetonin (3) comprised as much as $53 \%$ of the total impurities in reactions during which 8.6 mols and more of ammonia were introduced. The results of these experiments are listed in Table II and Fig. 1.

Table II. The effect of the amount of ammonia on the purity and yield of $\mathbf{1}$.

\begin{tabular}{lll}
\hline $\begin{array}{l}\text { Ammonia } \\
{[\mathrm{mols}]}\end{array}$ & $\begin{array}{l}\text { Purity } \\
{[\%]}\end{array}$ & $\begin{array}{l}\text { Yield of } 1 \\
{[\%]}\end{array}$ \\
\hline 4.0 & 94 & $15^{\mathrm{c}}(61)^{\mathrm{d}}$ \\
6.0 & 90 & $21^{\mathrm{c}}(52)^{\mathrm{d}}$ \\
$8.2^{\mathrm{e}}$ & 85 & $48^{\mathrm{f}}(76)^{\mathrm{d}}$ \\
8.6 & 50 & $22^{\mathrm{f}}(37)^{\mathrm{d}}$ \\
9.0 & 49 & $20^{\mathrm{f}}(33)^{\mathrm{d}}$ \\
\hline
\end{tabular}

a Per $1000 \mathrm{~g}$ of acetone and $400 \mathrm{~g}$ calcium chloride. b As determined by gas chromatography. ' Based on the amount of $\mathbf{1}$ isolated after solidification of the crude $\mathbf{1}$ in carbon tetrachloride, without taking into account the unreacted acetone, as determined by gas chromatography. d Yield taking into account the unreacted acetone, as determined by gas chromatography. e Optimized reaction conditions (see our first paper concerning triacetoneamine ${ }^{2}$ ). ${ }^{\mathrm{f}}$ Based on the amount of $\mathbf{1}$ distilled from the crude reaction mixture, without taking into account the unreacted acetone, as determined by gas chromatography.

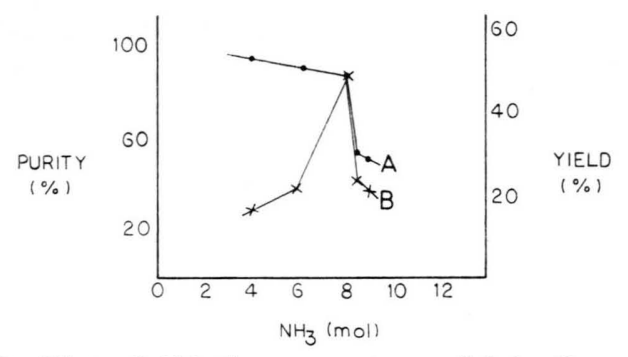

Fig. 1. Plot of (A) the percentage of $\mathbf{1}$ in the crude product and (B) the yield (\%) of $\mathbf{1}$ isolated from the crude product versus the moles of ammonia introduced.

A typical gas chromatographic analysis of the crude product obtained from the reaction employing 9 mols of ammonia is shown in Fig. 2.

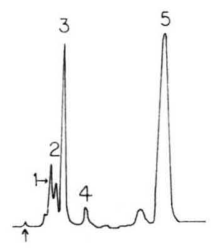

Fig. 2. Gas chromatographic analysis of the crude product obtained from the reaction employing 9 mols of ammonia. Arrow indicates injection of sample 1) Mesityl oxide. 2) Diacetoneamine (5). 3) Acetonin (3). 4) Diacetone alcohol (4). 5) Triacetoneamine (1).

The temperature at which the condensation of acetone with ammonia in the presence of calcium chloride takes place was found to have a pronounced effect on the purity and the weight yield of 1 . During the reaction in which ammonia was introduced at low temperature, the following cycle was observed. The reaction mixture was kept at $5-20{ }^{\circ} \mathrm{C}$ by means of an ice/sodium chloride bath for 12 hours, including the time of the introduction of ammonia, then at $20-23{ }^{\circ} \mathrm{C}$ for 12 hours during which time no ammonia was introduced. This cycle was repeated two additional times during the three-day period of introduction of ammonia (see experiment 8). From the reaction performed under these conditions, a product of only $45 \%$ purity was obtained. The reaction mixture acquired a bright orange-red color, and often converted from a heterogeneous to a homogeneous and back to a heterogeneous state during the three days of introduction of ammonia. Acetonin (3) comprised $55 \%$ of the total impurities, or $30 \%$ of the crude 1 . A typical gas chromatographic analysis of such a crude product is shown in Fig. 3. It was difficult to isolate pure triacetoneamine (1) from any crude product of purity less than $75 \%$. In this case, compound 1 could not be ob- 
tained by solidification of the crude product by addition of an equal volume of carbon tetrachloride. In general, distillation was the preferred method for the isolation of $\mathbf{1}$.

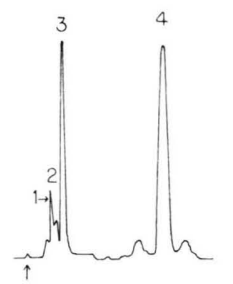

Fig. 3. Gas chromatographic analysis of the crude product obtained from the reaction performed at $0-23{ }^{\circ} \mathrm{C}$. Arrow indicates injection of sample 1) Mesityl oxide. 2) Diacetoneamine (5). 3) Acetonin (3). 4) Triacetoneamine $(\mathbf{1})$.

An entirely different effect was observed in the case that the reaction was performed at elevated temperatures. Thus, when the reaction mixture was kept at $59 \pm 1{ }^{\circ} \mathrm{C}$ during the entire seven-day period, the purity of 1 increased from $85 \%$ to $94 \%$, although the weight yield dropped from $48 \%$ to $21 \%$ (see experiment 9 ). In this case as much as $42 \%$ of the introduced ammonia escaped from the reaction mixture. If more ammonia, e.g. a total of 11.2 mols was introduced to compensate for that loss, no significant decrease in the purity of the product was observed. This result was surprising in view of the fact that, at room temperature, the introduction of an additional amount of only 0.4 mols ammonia in excess to that used under the optimized conditions, i.e. 8.6 mols rather than $8.2 \mathrm{mols}$, brought about a sharp decrease in the purity of crude 1 from $85 \%$ to $50 \%$. Furthermore, a decrease in weight yield was noted, and more ammonia escaped from the reaction mixture. As can be seen in both experiments 9 and
10 (see Experimental Section), the prolonged time at $59{ }^{\circ} \mathrm{C}$ also brought about a reduction in the amount of 1 in the reaction mixture. Thus, as detected by gas chromatography, the percentage of 1 in the reaction mixture attained a maximum on either the fourth or fifth day, then steadily decreased during the remaining days. In the case that the reaction mixture was kept at $59{ }^{\circ} \mathrm{C}$ for 20 hours following each introduction of ammonia, the loss of 1 was prevented and only $15 \%$ of the total ammonia introduced was lost. However, the purity of $\mathbf{1}$ decreased to $80 \%$. However, if the reaction mixture was kept at $59{ }^{\circ} \mathrm{C}$ only during the three days of the introduction of ammonia, the purity of $\mathbf{1}$ increased to $90 \%$ but $37 \%$ of the ammonia introduced was lost and the weight yield was reduced to $23 \%$. The yield and purity of $\mathbf{1}$ could be optimized if the reaction mixture was kept at $59{ }^{\circ} \mathrm{C}$ only during the time of introduction of ammonia, i.e. during the 45-60 minutes of each of the first four days of the seven-day reaction period. The results of these experiments are listed in Table III. A typical gas chromatographic analysis of the crude product obtained from the optimized experiment performed at $59{ }^{\circ} \mathrm{C}$ (experiment 13) is shown in Fig. 4.

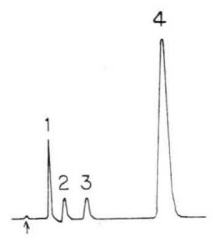

Fig. 4. Gas chromatographic analysis of the crude product obtained from the reaction kept at $59^{\circ} \mathrm{C}$ during the introduction of ammonia. Arrow indicates injection of sample 1) Mesityl oxide. 2) Acetonin (3).

3) Diacetone alcohol (4). 4) Triacetoneamine.

Table III. Effect of temperature on the purity and yield of $\mathbf{1}$.

\begin{tabular}{lllll}
\hline $\begin{array}{l}\text { Moles } \mathrm{NH}_{3} \text { per } \\
1000 \mathrm{~g} \text { acetone }\end{array}$ & $\begin{array}{l}\text { Conditions } \\
\text { at } 59^{\circ} \mathrm{C}\end{array}$ & $\begin{array}{l}\% \mathrm{NH}_{3} \\
\text { lost }\end{array}$ & $\begin{array}{l}\text { Purity of } \mathbf{1}^{\mathrm{e}} \\
{[\%]}\end{array}$ & $\begin{array}{l}\text { Yield of 1 } \\
{[\%]}\end{array}$ \\
\hline 8.2 & $\mathrm{a}$ & 42 & 94 & $20^{\mathrm{f}}(72)^{\mathrm{g}}$ \\
11.4 & $\mathrm{a}$ & 46 & 91 & $26^{\mathrm{h}}(61)^{\mathrm{g}}$ \\
$8.2^{\mathrm{i}}$ & $\mathrm{b}$ & 20 & 93 & $34^{\mathrm{f}}(84)^{\mathrm{g}}$ \\
8.2 & $\mathrm{c}$ & 37 & 90 & $23^{\mathrm{f}}(70)^{\mathrm{g}}$ \\
8.2 & d & 15 & 80 & $39^{\mathrm{h}}(60)^{\mathrm{g}}$ \\
\hline
\end{tabular}

a Reaction mixture maintained at $59 \pm 1{ }^{\circ} \mathrm{C}$ during the entire seven-day period (experiments 9 and 10 ). ${ }^{\mathrm{b}} \mathrm{Re}$ action mixture maintained at $59 \pm 1{ }^{\circ} \mathrm{C}$, only during the time of addition of ammonia (experiment 13). $\mathrm{c}$ Reaction mixture maintained at $59+1{ }^{\circ} \mathrm{C}$, only during the three days of addition of ammonia (experiment 12). d Reaction mixture maintained at $59+1{ }^{\circ} \mathrm{C}$ for $20 \mathrm{~h}$ following each addition of ammonia. The remaining tirne. the mixture was kept at $23-25{ }^{\circ} \mathrm{C}$ (experiment 11). e As determined by gas chromatography. ${ }^{\mathrm{f}}$ The yield is based on the amount of crude $\mathbf{1}$ obtained, adjusted for purity, without taking into account the acetone recovered by distillation. $\mathrm{g}$ Yield taking into account the unreacted acetone recovered by distillation. $\mathrm{h}$ The yield is based on the amount of $\mathbf{1}$ obtained after distillation of the crude reaction mixture, without taking into account the unreacted acetone. i Optimized reaction conditions. 
In all reactions which were performed at the elevated temperature, the sharp increase of approximately $40 \%$ in the amount of 1 which took place during the reaction under optimized conditions at room temperature after the final introduction of ammonia (see experiment 1 of our first paper on triacetoneamine ${ }^{2}$ ) was not observed. In fact, during the reaction kept at $59{ }^{\circ} \mathrm{C}$ for the period of time of introduction of ammonia, the amount of $\mathbf{1}$ in the reaction mixture increased by only $11 \%$ in the time interval following the final introduction of ammonia (see experiment 13).

Depending on whether a larger weight yield or better purity of $\mathbf{1}$ is desired, the optimized reaction conditions either at room temperature or at $59{ }^{\circ} \mathrm{C}$, respectively, can be used to prepare triacetoneamine. Since at least $80 \%$ of the unreacted acetone is recoverable by distillation, the cost of the experiment can be minimized. An advantage of the reaction at $59{ }^{\circ} \mathrm{C}$ lies in the fact that the crude 1 is of sufficient purity to be used without further purification for the preparation ${ }^{6}$ of 4 -hydroxy$2,2,6,6$-tetramethylpiperidine (6) in $78-80 \%$ yield.

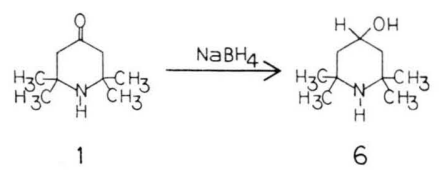

\section{Experimental}

The complete details on the reagents used and the method of analysis by gas chromatography are found in our first paper on the preparation of triacetoneamine ${ }^{2}$.

\section{Reaction at room temperature using 400 grams of} calcium chloride and 10 grams of ammonium chloride

General procedure A: Anhydrous ammonia $(140.0 \mathrm{~g}, 8.3 \mathrm{~mol})$ was introduced at room temperature in five portions over a period of five days to a well-stirred mixture of reagent grade acetone (1000 g, $17.3 \mathrm{~mol})$, anhydrous calcium chloride (400 g, 4-8 mesh size), and ammonium chloride $(10.0 \mathrm{~g}, 0.2 \mathrm{~mol})$. In appearance, the reaction mixture did not differ from the optimized reaction ${ }^{2}$. After the final introduction of ammonia, the thickened reaction mixture was left undisturbed for two days, then poured into $500 \mathrm{ml}$ of an aqueous solution containing $100 \mathrm{~g}$ sodium hydroxide. The mixture was stirred until an oil separated. The oil was decanted and the remaining caustic slurry washed with diethyl ether $(5 \times 200 \mathrm{ml})$. The combined oil and ethereal extracts were dried over magnesium sulfate. The drying agent was removed by filtration and the filtrate was concentrated on a rotating evaporator at $20-22{ }^{\circ} \mathrm{C}(12-15$ torr) to give $540 \mathrm{~g}$ of crude 1 . The purity of this material was $85 \%$, as determined by gas chromatography. The acetone as determined by gas chromatography, plus that converted to 1 and by-products was accountable to $93 \%$. The crude material was distilled to give $406 \mathrm{~g}$ (45\% yield based on starting acetone, or 70\% yield taking into account the acetone determined by gas chromatography) of $1, \mathrm{~m} . \mathrm{p} .33-35{ }^{\circ} \mathrm{C}$.

\section{Reaction at room temperature using 400 grams of} calcium chloride and 100 grams of ammonium chloride

Anhydrous ammonia (138.0 g, $8.1 \mathrm{~mol})$ was introduced at room temperature in four portions over a period of four days to a well-stirred mixture of reagent grade acetone $(1000 \mathrm{~g}, 17.3 \mathrm{~mol})$, anhydrous calcium chloride (400 g, 4-8 mesh size), and ammonium chloride $(100 \mathrm{~g}, 1.9 \mathrm{~mol})$. Following the first introduction of ammonia $(32.0 \mathrm{~g}, 1.9 \mathrm{~mol})$, the reaction mixture became heterogeneous, then homogeneous after $20 \mathrm{~h}$ of stirring at room temperature. Thereafter, the reaction mixture did not differ in appearance from the optimized reaction ${ }^{2}$. After the final introduction of ammonia, the thickened reaction mixture was left undisturbed for three days. Following the workup as described in the general procedure $\mathrm{A}$, there was obtained $598 \mathrm{~g}$ of crude 1 . The purity of 1 , as determined by gas chromatography, was $72 \%$. The acetone determined by gas chromatography, plus that converted to 1 and by-products was accountable to $93 \%$. The crude oil was of such an inferior quality that crystallization of solid $\mathbf{1}$ could not be achieved from carbon tetrachloride. Distillation of this oil afforded $310 \mathrm{~g} \mathrm{(35 \%} \mathrm{yield} \mathrm{based} \mathrm{on} \mathrm{starting} \mathrm{acetone,} \mathrm{or} 50 \%$ yield taking into account the acetone determined by gas chromatography) of $1, \mathrm{~m} . \mathrm{p} .34-36{ }^{\circ} \mathrm{C}$.

3. Reaction at room temperature using 400 grams of calcium chloride and 400 grams of ammonium chloride

Anhydrous ammonia (140.0 g, $8.3 \mathrm{~mol})$ was introduced at room temperature in five portions over a period of five days to a well-stirred mixture of reagent grade acetone $(1000 \mathrm{~g}, 17.3 \mathrm{~mol})$, anhydrous calcium chloride (400 g, 4-8 mesh size), and ammonium chloride $(400 \mathrm{~g}, 7.5 \mathrm{~mol})$. The reaction mixture did not differ in appearance from the optimized reaction ${ }^{2}$ until the last (fifth) day, when during the time of the final introduction of ammonia, the reaction mixture did not thicken, but loosened without becoming heterogeneous. After the final introduction, the reaction mixture was left undisturbed for two days. Following the workup, as described in the general procedure $\mathrm{A}$, there was obtained $578 \mathrm{~g}$ of crude 1 . The purity of 1 , as determined by gas chromatography, was $70 \%$. Unreacted acetone determined by gas chromatography, plus that converted to 1 and by-products was accountable to $95 \%$. Distillation of the crude 1 afforded $200 \mathrm{~g} \mathrm{(22 \%} \mathrm{yield} \mathrm{based} \mathrm{on} \mathrm{starting} \mathrm{acetone,}$ 
or $34 \%$ yield taking into account the acetone determined by gas chromatography) of 1, b.p. $50-58{ }^{\circ} \mathrm{C}$ (1 torr), m.p. $35-36^{\circ} \mathrm{C}$. The additional details of this experiment, including the amount of 1 formed each day and the appearance of the reaction mixture follow.

\begin{tabular}{|c|c|c|c|c|c|}
\hline Day & $\begin{array}{l}\text { Ammonia introduced } \\
\text { per day } \\
\mathrm{g}[\mathrm{mols}]\end{array}$ & $\begin{array}{l}\text { Total ammonia } \\
\text { in reaction mixture } \\
{[\%]}\end{array}$ & $\begin{array}{l}\text { Duration of } \\
\text { introduction } \\
{[\mathrm{min}]}\end{array}$ & $\begin{array}{l}\text { Temperature } \\
\text { during introduction } \\
{\left[{ }^{\circ} \mathrm{C}\right]}\end{array}$ & $\begin{array}{l}\mathbf{1} \\
\text { Present } \\
{[\%]}\end{array}$ \\
\hline $1^{\mathrm{a}}$ & $35(2.1)$ & 25 & 50 & $27-38$ & $0^{\mathrm{f}}$ \\
\hline $2^{\mathrm{b}}$ & 19 (1.1) & 39 & 45 & 26-39 & trace \\
\hline $3^{\mathrm{c}}$ & $20(1.2)$ & 53 & 65 & $26-37$ & $<1$ \\
\hline $4^{\mathrm{d}}$ & $24(1.4)$ & 70 & 50 & $27-38$ & 1 \\
\hline $5^{\mathrm{e}}$ & $42(2.5)$ & $100(8.3 \mathrm{~mol})$ & 60 & $26-43$ & 3 \\
\hline 6 & - $12=0$ & & & & 6 \\
\hline 7 & & & & & 16 \\
\hline 8 & & & & & $22^{\mathrm{g}}$ \\
\hline
\end{tabular}

a The reaction mixture was a heterogeneous mixture of white solid and colorless liquid after the first introduction which becomes homogeneous overnight. ${ }^{\mathrm{b}}$ The reaction mixture was creamy and homogeneous. $\mathrm{c}$ The reaction mixture was yellow and homogeneous. $\mathrm{d}$ The reaction mixture thickened considerably during the fourth introduction. e The reaction mixture loosened overnight, then thickened during the first half of the last introduction, and finally loosened without becoming heterogeneous. ${ }^{\mathrm{f}}$ The analyses for $\mathbf{1}$ in the reaction mixture were always performed by gas chromatography approximately $24 \mathrm{~h}$ after the previous day's introduction of ammonia, i.e. just prior to the next introduction. $\mathrm{g}$ The yield was based on $\mathbf{1}$ obtained after distillation of the crude product without taking into account the unreacted acetone as determined by gas chromatography. The yield was $34 \%$ on taking into account this unreacted acetone.

\section{Reaction at room temperature using 4 mols of ammonia}

Anhydrous ammonia $(74.0 \mathrm{~g}, 4.4 \mathrm{~mol})$ was introduced at room temperature in three portions over a period of three days to a well-stirred mixture of reagent grade acetone $(1000 \mathrm{~g}, 17.3 \mathrm{~mol})$ and anhydrous calcium chloride (400 g, 4-8 mesh size). Following the final introduction of ammonia, the thickened reaction mixture was left to stand undisturbed for an additional four days. After the workup as described in the general procedure A, there was obtained $206 \mathrm{~g}$ of crude 1, as a semisolid material. The purity of this product, as determined by gas chromatography was $94 \%$. Unreacted acetone determined by gas chromatography plus that converted to $\mathbf{1}$ and by-products was accountable to $99 \%$. Solidification of the crude product in carbon tetrachloride afforded $130 \mathrm{~g}$ (15\% yield based on starting acetone, or $61 \%$ yield based on acetone determined by gas chromatography) of $\mathbf{1}$, m.p. $34-36^{\circ} \mathrm{C}$.

\section{Reaction at room temperature using 6 mols of ammonia}

Anhydrous ammonia (104 g, $6.1 \mathrm{~mol})$ was introduced at room temperature in three portions over a period of three days to a well-stirred mixture of reagent grade acetone $(1000 \mathrm{~g}, 17.3 \mathrm{~mol})$ and anhydrous calcium chloride (400 g, 4-8 mesh size). Following the final introduction of ammonia, the thickened reaction mixture was left undisturbed for an additional four days. After the workup as described in the general procedure $A$, there was obtained $350 \mathrm{~g}$ of crude 1, as a semi-solid material. The purity of the product, as determined by gas chromatography, was $90 \%$. Unreacted acetone as determined by gas chromatography plus that converted to 1 and by-products was accountable to $99 \%$. Solidification of the crude 1 in carbon tetrachloride afforded $185 \mathrm{~g}(21 \%$ yield based on starting acetone, or $52 \%$ yield taking into account the acetone determined by gas chromatography) of 1, m.p. $34-36{ }^{\circ} \mathrm{C}$.

\section{Reaction at room temperature using $8.6 \mathrm{~mol}$ of ammonia}

Anhydrous ammonia $(146.0 \mathrm{~g}, 8.6 \mathrm{~mol})$ was introduced in three portions over a period of three days to a well-stirred mixture of reagent grade acetone (1000 g, $17.3 \mathrm{~mol}$ ) and anhydrous calcium chloride (400 g, 4-8 mesh size). Following the final introduction of ammonia, the loosened reaction mixture was left undisturbed for four days. After the workup as described in the general procedure A, there was obtained $537 \mathrm{~g}$ of crude 1 . The purity of 1 , as determined by gas chromatography was $50 \%$. Unreacted acetone plus that converted to 1 and byproducts, was accountable to $97 \%$. No crystallization of solid 1 could be achieved from carbon tetrachloride. The yield of 1 , as determined by gas chromatography, was $27 \%$, based on starting acetone, or $48 \%$ taking into account the acetone as determined by gas chromatography. Distillation of the crude 1 afforded $200 \mathrm{~g}(22 \%$ yield based on starting acetone, or $37 \%$ yield taking into account the acetone determined by gas chromatography) of 1 , b.p. $50-56{ }^{\circ} \mathrm{C}$ (1 torr), m.p. $34-36{ }^{\circ} \mathrm{C}$.

\section{Reaction at room temperature using 9 mols of ammonia}

Anhydrous ammonia (157.0 g, $9.2 \mathrm{~mol}$ ) was introduced at room temperature in four portions over a 
period of four days to a well-stirred mixture of reagent grade acetone $(1000 \mathrm{~g}, 17.3 \mathrm{~mol})$ and anhydrous calcium chloride (400 g, 4-8 mesh). During the time of the introduction of ammonia, the reaction mixture never thickened as had been observed during the optimized reaction ${ }^{2}$ and, in the time of the introduction of ammonia on the final (fourth) day, became completely heterogeneous. Stirring was then discontinued, and the reaction mixture was left undisturbed for three days. After the workup as described in the general procedure A, there was obtained $536 \mathrm{~g}$ of crude 1 . The purity of 1 , as determined by gas chromatography, was $49 \%$. Acetonin (3) comprised $53 \%$ of the total impurities. Unreacted acetone determined by gas chromato- graphy plus that converted to $\mathbf{1}$ and byproducts was accountable to $99 \%$. The crude 1 was of such an inferior quality that no crystallization of solid 1 could be achieved from carbon tetrachloride. The yield of $\mathbf{1}$, as determined by gas chromatography, was $29 \%$, based on starting acetone, or $48 \%$ taking into account the acetone as determined by gas chromatography. Distillation of the crude 1 afforded $180 \mathrm{~g}(20 \%$ yield based on starting acetone, or $33 \%$ yield taking into account the acetone as determined by gas chromatography) of 1 , b. p. $50-56{ }^{\circ} \mathrm{C}$ (1 torr), m.p. $35-36{ }^{\circ} \mathrm{C}$. The additional details of this experiment, including the amount of 1 formed each day and the appearance of the reaction mixture follow.

\begin{tabular}{|c|c|c|c|c|c|}
\hline Day & $\begin{array}{l}\text { Ammonia introduced } \\
\text { per day } \\
\mathrm{g}[\text { mols }]\end{array}$ & $\begin{array}{l}\text { Total ammonia } \\
\text { in reaction mixture } \\
{[\%]}\end{array}$ & $\begin{array}{l}\text { Duration of } \\
\text { introduction } \\
{[\mathrm{min}]}\end{array}$ & $\begin{array}{l}\text { Temperature } \\
\text { during introduction } \\
{\left[{ }^{\circ} \mathrm{C}\right]}\end{array}$ & $\begin{array}{l}\mathbf{1} \\
\text { Present } \\
{[\%]}\end{array}$ \\
\hline $1^{\mathrm{a}}$ & $34(2.0)$ & 22 & 60 & $28-37$ & $0^{\mathrm{e}}$ \\
\hline $2^{\mathrm{b}}$ & $43(2.5)$ & 49 & 50 & $26-42$ & 1 \\
\hline $3^{c}$ & $37(2.2)$ & 73 & 30 & $26-36$ & 2 \\
\hline $4^{\mathrm{d}}$ & $43(2.5)$ & $100(9.2 \mathrm{~mol})$ & 60 & $26-45$ & 6 \\
\hline 5 & & & & & 13 \\
\hline 6 & & & & & 13 \\
\hline 7 & & & & & 16 \\
\hline 8 & & & & & $20^{f}$ \\
\hline
\end{tabular}

a The reaction mixture was heterogeneous after the first introduction but became homogeneous prior to the second. ${ }^{b}$ The cream-colored mixture did not thicken. c The orange-colored mixture loosened during the third introduction. d The mixture became heterogeneous during the final introduction, i.e. a red oil and a white solid resulted. e The analyses for 1 in the reaction mixture were always performed by gas chromatography approximately $24 \mathrm{~h}$ after the previous day's introduction of ammonia, i.e. just prior to the next introduction. ${ }^{\mathrm{f}}$ The yield was based on 1 obtained after distillation of the crude product without taking into account the unreacted acetone as determined by gas chromatography. The yield was $33 \%$ on taking into account this unreacted acetone.

\section{Reaction at $0-20^{\circ} \mathrm{C}$ during introduction of ammonia}

Anhydrous ammonia (136.0 g, $8.0 \mathrm{~mol})$ was introduced at $5-20^{\circ} \mathrm{C}$ in three portions over a period of three days to a well-stirred mixture of reagent grade acetone $(1000 \mathrm{~g}, 17.3 \mathrm{~mol})$ and anhydrous calcium chloride (400 g, 4-8 mesh size). Each day, the reaction mixture was kept in an ice/salt bath for approximately $12 \mathrm{~h}$, including the time of introduction of ammonia, then at $20-23{ }^{\circ} \mathrm{C}$ for the following $12 \mathrm{~h}$. This cycle was repeated during the first three days. After the final introduction of ammonia, on the third day, the stirring was discontinued, and the reaction mixture was left undisturbed for an additional four days, while maintaining the ice/salt bath for $12 \mathrm{~h}$ per day as during the period of introduction. Following the workup as described in the general procedure A, there was obtained $634 \mathrm{~g}$ of crude 1 . The purity of 1 as determined by gas chromatography was $45 \%$. Acetonin (3) comprised $55 \%$ of the total impurities. Unreacted acetone, identified by gas chromatography, plus that converted to $\mathbf{1}$ and by-products was accountable to $98 \%$. The crude product 1 was of such an inferior quality that no crystallization of solid 1 could be achieved from carbon tetrachloride.
Distillation of the crude reaction mixture afforded $181 \mathrm{~g},(20 \%$ yield based on total acetone, or $28 \%$ yield taking into account the acetone determined by gas chromatography) of 1 b. p. $51-57^{\circ} \mathrm{C}$ (1 torr), m.p. $34-36{ }^{\circ} \mathrm{C}$. The additional details of this experiment including the amount of $\mathbf{1}$ formed each day and the appearance of the reaction mixture follow (see top of page 344).

\section{Reaction at elevated temperature seven days at $59^{\circ} \mathrm{C}$ using 8.2 mols of ammonia}

General procedure B: Anhydrous ammonia $(140.0 \mathrm{~g}, 8.2 \mathrm{~mol})$ was introduced at $59{ }^{\circ} \mathrm{C}$ in six portions over a period of three days to a wellstirred mixture of reagent grade acetone (1000 g, $17.3 \mathrm{~mol}$ ) and anhydrous calcium chloride (400 g, 4-8 mesh size). After the final introduction of ammonia, the reaction mixture was left undisturbed at $59{ }^{\circ} \mathrm{C}$ for an additional four days. The amount of ammonia lost each day was determined by trapping the escaping gas with an aqueous hydrogen chloride solution. The solution containing the ammonium chloride formed by the escaping ammonia was concentrated on a rotating evaporator at $23-30{ }^{\circ} \mathrm{C}$ (12-15 torr). The remaining solid was washed 


\begin{tabular}{|c|c|c|c|c|c|}
\hline Day & $\begin{array}{l}\text { Ammonia introduced } \\
\text { per day } \\
\mathrm{g}[\text { mols }]\end{array}$ & $\begin{array}{l}\text { Total ammonia } \\
\text { in reaction mixture } \\
{[\%]}\end{array}$ & $\begin{array}{l}\text { Duration of } \\
\text { introduction } \\
{[\mathrm{min}]}\end{array}$ & $\begin{array}{l}\text { Temperature } \\
\text { during introduction } \\
{\left[{ }^{\circ} \mathrm{C}\right]}\end{array}$ & $\begin{array}{l}\mathbf{1} \\
\text { Present } \\
{[\%]}\end{array}$ \\
\hline $1^{\mathrm{a}}$ & $30(1.8)$ & 29 & 55 & $5-15$ & $0^{\mathrm{d}}$ \\
\hline $2^{\mathrm{b}}$ & $46(2.7)$ & 56 & 30 & $5-20$ & 0 \\
\hline $3^{\mathrm{c}}$ & $60(3.5)$ & $100(8.0 \mathrm{~mol})$ & 60 & $5-20$ & 3 \\
\hline 4 & & & & & 6 \\
\hline 5 & & & & & 10 \\
\hline 6 & & & & & 12 \\
\hline 7 & & & & & 14 \\
\hline 8 & & & & & $20^{\mathrm{e}}$ \\
\hline
\end{tabular}

a Reaction mixture turned heterogeneous $2 \mathrm{~h}$ after the introduction. b Mixture remained heterogeneous, $i . e$. orange liquid and white solid. c The reaction mixture had turned homogeneous overnight before the final introduction. It rapidly separated into the heterogeneous system of a red-orange liquid and nearly white solid during the final introduction. d The analyses for $\mathbf{1}$ in the reaction mixture were always performed by gas chromatography approximately $24 \mathrm{~h}$ after the previous day's introduction of ammonia, i.e. just prior to the next introduction. $\mathrm{e}$ The yield was based on $\mathbf{1}$ obtained after distillation of the crude product without taking into account the unreacted acetone as determined by gas chromatography. The yield was $28 \%$ on taking into account the unreacted acetone.

repeatedly with acetone to remove water and hydrogen chloride, then air-dried.

The apparatus was then converted for distillation, and the reaction mixture stirred at $35^{\circ} \mathrm{C}$ under reduced pressure (100 torr). The unreacted acetone was collected in two traps chilled by isopropyl alcohol/dry ice baths. All precautions were taken to exclude moisture from the system. In this manner was collected $720 \mathrm{~g}(72 \%$ based on moles initially used) of acetone. To the remaining cake was added $500 \mathrm{ml}$ of an aqueous solution containing $100 \mathrm{~g}$ sodium hydroxide. The mixture was vigorously stirred. The oil was decanted. The remaining aqueous slurry was extracted with diethyl ether $(5 \times 200 \mathrm{ml})$. The combined oil and ethereal extracts were dried over anhydrous magnesium sulfate. The drying agent was removed by filtration. Removal of the solvent on a rotating evaporator at $25^{\circ} \mathrm{C}(12-15$ torr $)$ gave $190 \mathrm{~g}$ of crude $1, \mathrm{~m}$. p. $30-33{ }^{\circ} \mathrm{C}$. The purity of 1 , as determined by gas chromatography, was $94 \%$. The yield of $\mathbf{1}$ adjusted for purity and based on the crude weight without taking into account the recovered acetone was $20 \%$. The yield of 1 adjusted for purity taking into account the unreacted acetone recovered by distillation $(720 \mathrm{~g}, 72 \%$ based on moles initially used) was $72 \%$. The material was of sufficient purity to be used in the reduction of 1 to 4-hydroxy-2,2,6,6-tetramethylpiperidine (6) with sodium borohydride in $80 \%$ yield.

\section{Reaction at elevated temperature. Seven days at $59{ }^{\circ} \mathrm{C}$ using 11.4 mols of ammonia}

Anhydrous ammonia (195.0 g, $11.4 \mathrm{~mol})$ was introduced at $59{ }^{\circ} \mathrm{C}$ in seven portions over a period of four days to a well-stirred mixture of reagent grade acetone $(1000 \mathrm{~g}, 17.3 \mathrm{~mol})$ and anhydrous calcium chloride (400 g, 4-20 mesh size). After the final introduction of ammonia, the stirring was discountinued, and the reaction mixture was left undisturbed at $59{ }^{\circ} \mathrm{C}$ for another three days. The amount of ammonia escaping from the reaction mixture was determined as ammonium chloride (experiment 9). The reaction mixture was then worked up, as described in the general procedure B. Thus was obtained $275 \mathrm{~g}$ of crude 1 . The purity of 1 as determined by gas chromatography was $91 \%$. Unreacted acetone as determined by gas chromatography, plus that converted to $\mathbf{1}$ and by-products was accountable to $93 \%$. Unreacted acetone recovered by distillation $(580 \mathrm{~g}, 58 \%$ based on moles initially used) plus that converted to 1 was accountable to $85 \%$. The crude 1 was distilled to give $230 \mathrm{~g}$ $(26 \%$ yield based on total acetone, or $61 \%$ yield taking into account the acetone recovered by distillation) of 1, b.p. $50-58^{\circ} \mathrm{C}$ (1 torr), m.p. $34-36{ }^{\circ} \mathrm{C}$.

\section{Reaction at $59{ }^{\circ} \mathrm{C}$ only following the introduction of ammonia}

Anhydrous ammonia (140.0 g, $8.2 \mathrm{~mol}$ ) was introduced at room temperature in four portions over a period of three days to a well-stirred mixture of reagent grade acetone $(1000 \mathrm{~g}, 17.3 \mathrm{~mol})$ and anhydrous calcium chloride (400 g, 4-20 mesh size). During each introduction of ammonia, the temperature of the reaction mixture was not allowed to exceed $40^{\circ} \mathrm{C}$. Following each introduction, the reaction mixture was kept at $59{ }^{\circ} \mathrm{C}$ for $20-24 \mathrm{~h}$, then allowed to cool down to ambient temperature prior to the next introduction. After the final addition, the reaction mixture was kept at $59^{\circ} \mathrm{C}$ for $20 \mathrm{~h}$, then left undisturbed at ambient temperature for four days. The amount of ammonia escaping from the reaction mixture during the 3 -day period it was kept at $59{ }^{\circ} \mathrm{C}$ was determined as ammonium chloride (experiment 9). After the workup as described in the general procedure $A$, there was obtained $582 \mathrm{~g}$ of crude 1 . The purity of 1 , as determined by gas chromatography, was $80 \%$. Unreacted acetone as determined by gas chromatography, plus that converted to $\mathbf{1}$ and by-products 
was accountable to $99 \%$. The crude reaction mixture was solidified in carbon tetrachloride to give $290 \mathrm{~g}(33 \%$ yield based on total acetone, or $49 \%$ yield taking into account the acetone determined by gas chromatography) of $1, \mathrm{~m}$. p. $34-35^{\circ} \mathrm{C}$. If, instead, the crude 1 was distilled, there was obtained $352 \mathrm{~g}(39 \%$ yield based on total acetone, or $60 \%$ yield taking into account the acetone determined by gas chromatography) of 1, b.p. $50-55^{\circ} \mathrm{C}$ (1 torr), m.p. $34-36{ }^{\circ} \mathrm{C}$.

\section{Reaction at $59{ }^{\circ} \mathrm{C}$ only during the days of introduction of ammonia}

Anhydrous ammonia (140.0 g, $8.2 \mathrm{~mol}$ ) was introduced at $59{ }^{\circ} \mathrm{C}$ in seven portions over a period of four days to a well-stirred mixture of reagent grade acetone $(1000 \mathrm{~g}, 17.3 \mathrm{~mol})$ and anhydrous calcium chloride (400 g, 4-20 mesh size). After the final introduction of ammonia, both stirring and heating were discontinued, and the reaction mixture was left undisturbed at ambient temperature for three days. The amount of ammonia escaping from the reaction mixture during the 4-day period it was kept at $59{ }^{\circ} \mathrm{C}$ was determined as ammonium chloride (experiment 9). The reaction mixture was worked up as described in the general procedure B. Thus was obtained $233 \mathrm{~g} \quad(23 \%$ yield based on total acetone, taking into account the purity, or $70 \%$ yield taking into account the acetone as determined by gas chromatography) of crude 1, m.p. $32-34{ }^{\circ} \mathrm{C}$. The purity of 1 , as determined by gas chromatography was $90 \%$. Unreacted acetone (666 g, 66\% based on moles initially used) recovered by distillation, plus that converted to 1 was accountable to $70 \%$. The crude 1 was of sufficient purity to be used in the reduction of 1 to 4-hydroxy-2,2,6,6-tetramethyl-piperidine (6) with sodium borohydride in $73 \%$ yield.

\section{Reaction at $59{ }^{\circ} \mathrm{C}$ only during the time of the introduction of ammonia}

Anhydrous ammonia (140.0 g, $8.2 \mathrm{~mol}$ ) was introduced at $59{ }^{\circ} \mathrm{C}$ in six portions over a period of four days to a well-stirred mixture of reagent grade acetone $(1000 \mathrm{~g}, 17.3 \mathrm{~mol})$ and anhydrous calcium chloride (400 g, 4-20 mesh size). In the time intervals between the additions, the reaction mixture was kept at room temperature $\left(23-35^{\circ} \mathrm{C}\right)$. The amount of ammonia escaping from the reaction mixture during the four-day period of introduction was determined as ammonium chloride (experiment 9). Following the final introduction of ammonia, the thickened reaction mixture was left undisturbed at $23-25^{\circ} \mathrm{C}$ for 3 days. After the workup, as described in the general procedure B, there was obtained $318 \mathrm{~g}$ (34\% yield based on total acetone, taking into account the purity, or $95 \%$ yield taking into account the acetone as determined by gas chromatography) of crude 1, m.p. $33-35{ }^{\circ} \mathrm{C}$. The purity of $\mathbf{1}$ as determined by gas chromatography was $94 \%$. Unreacted acetone $(600 \mathrm{~g}, 60 \%$ based on moles initially used) recovered by distillation plus that converted to 1 was accountable to $84 \%$. The crude 1 was of sufficient purity to be used in the reduction of 1 to 4 -hydroxy-2,2,6,6-tetramethylpiperidine (6) with sodium borohydride in $80 \%$ yield. The additional details of this experiment, including the amount of $\mathbf{1}$ formed each day and the appearance of the reaction mixture follow.

\begin{tabular}{|c|c|c|c|c|c|}
\hline Day & $\begin{array}{l}\text { Ammonia introduced } \\
\text { per day } \\
\mathrm{g}[\mathrm{mols}]\end{array}$ & $\begin{array}{l}\text { Total ammonia } \\
\text { in reaction mixture } \\
{[\%]}\end{array}$ & $\begin{array}{l}\text { Duration of } \\
\text { introduction } \\
{[\mathrm{min}]}\end{array}$ & $\begin{array}{l}\text { Ammonia escaping } \\
\text { from reaction mixture } \\
{[\mathrm{mols}]}\end{array}$ & $\begin{array}{l}\mathbf{1} \\
\text { Present } \\
{[\%]}\end{array}$ \\
\hline $1^{\mathrm{a}}$ & $14(0.8)$ & 10 & 45 & $0.1^{\mathrm{e}}$ & $0^{\mathrm{f}}$ \\
\hline $2^{\mathrm{b}}$ & $\begin{array}{l}\text { a) } 17(1.0) \\
\text { b) } 30(1.8)\end{array}$ & 43 & $\begin{array}{l}\text { a) } 60 \\
\text { b) } 50\end{array}$ & 0.4 & $<1$ \\
\hline $3^{\mathrm{c}}$ & $\begin{array}{l}\text { a) } 33(1.9) \\
\text { b) } 13(0.8)\end{array}$ & 76 & $\begin{array}{l}\text { a) } 60 \\
\text { b) } 50\end{array}$ & 0.5 & 10 \\
\hline $4^{\mathrm{d}}$ & $33(1.9)$ & $100(8.2 \mathrm{~mol})$ & 60 & $0.7 \mathrm{~g}$ & 23 \\
\hline 5 & & & & & 27 \\
\hline 6 & & & & & 32 \\
\hline 7 & & & & & 33 \\
\hline 8 & & & & & $34^{\mathrm{h}}$ \\
\hline
\end{tabular}

a No distinct phase separation took place during the introduction of ammonia. The mixture gradually became homogeneous during the $20 \mathrm{~h}$ prior to the second addition. $\mathrm{b}$ The reaction mixture was homogeneous and creamcolored. c The reaction mixture thickened during both introductions of ammonia. d The yellow homogeneous mixture thickened considerably during the introduction. e The moles of ammonia which escaped from the reaction mixture were determined as ammonium chloride (see experiment 9). The determination for ammonia escaping was always performed approximately $24 \mathrm{~h}$ after the previous day's introduction of ammonia, i.e. just prior to the next introduction. ${ }^{\mathrm{f}}$ The analyses for $\mathbf{1}$ in the reaction mixture were always performed by gas chromatography approximately $24 \mathrm{~h}$ after the previous day's introduction of ammonia, i.e. just prior to the next introduction. $\mathrm{g}$ The total ammonia lost was $29 \mathrm{~g}(1.7 \mathrm{~mol})$, or $20 \%$ of the amount introduced. $\mathrm{h}$ The yield was based on crude 1 obtained, adjusted for purity, without taking into account the acetone recovered by distillation. The yield was $84 \%$ on taking into account this recovered acetone. 
This investigation was supported by grants from the Public Health Service, U.S. Department of Health, Education, and Welfare, GM 16741, and

1 G. Sosnovsky and M. Konieczny, Synthesis 1976, 735 .

2 G. Sosnovsky and M. Konieczny, Z. Naturforsch. 32 b, 328 [1977].

3 E. Matter, Helv. Chim. Acta 30, 1114 [1947]. from the Graduate School of the University of Wisconsin-Milwaukee.

4 R. B. Bradbury, N. C. Hancox, and H. H. Hatt, J. Chem. Soc. 1947, 1394.

5 I. B. Simon and V. P. Vvedenskit, Med. Prom. SSSR 5, 9 [1963]. 